\title{
Rare Renal Diseases Can Be Used as Tools to Investigate Common Kidney Disorders
}

\author{
Mariadelina Simeoni ${ }^{\mathrm{a}}$ Sara Damiano $^{\mathrm{b}}$ Giovanna Capolongo $^{\mathrm{b}}$ \\ Francesco Trepiccione $^{b}$ Miriam Zacchia $^{b}$ Giorgio Fuiano $^{a}$ \\ Giovambattista Capasso ${ }^{\text {b }}$ \\ a Department of Nephrology, Magna Graecia University Hospital, Catanzaro, and bepartment of Nephrology, \\ University of Campania "Luigi Vanvitelli," Naples, Italy
}

\section{Keywords}

Genetic kidney diseases · Hypertension · Salt sensitivity .

Steroid-resistant nephrotic syndrome $\cdot$ Tubulopathies importance of the study of rare diseases to better understand the molecular basis of more common and complex disorders leading to end-stage renal disease.

๑) 2017 S. Karger AG, Basel

\section{Introduction}

Rare diseases are considered a health problem since they are characterized by a high social impact due to the limited knowledge, clinical severity, and restricted therapeutic options associated with them. In particular, rare kidney diseases are associated with the development of chronic kidney disease (CKD) and its progression to endstage renal disease, requiring renal function substitution with dialysis or kidney transplantation. The early diagnosis and knowledge of the primary cause of a rare disorder are essential for improving the prognosis, especially if therapeutic options are available. In addition, an understanding of the molecular basis of the defect is important for the development of new targeted therapeutic tools. In

Contribution from the International Conference: The Kidney in Genetic and Rare Diseases, Naples, October 27-29, 2016.

\section{KARGER}

(C) 2017 S. Karger AG, Basel 
most of the cases, however, the diagnosis of a rare kidney disease is still quite difficult and requires considerable experience, and an underestimation of the prevalence of these pathologies might be supposed [1]. Nevertheless, the advent of next-generation sequencing technologies, in recent years, has improved the timing and the quality of the diagnosis of rare kidney diseases, also providing the opportunity to better understand molecular defects shared by both rare and common renal diseases.

The achievement of proteinuria reduction and an optimal blood pressure control are recognized therapeutic goals able to slow CKD progression [2]. Despite significant therapeutic advances, it is conceivable that there is still much to learn about the pathogenesis of major kidney diseases in order to find more effective and useful therapies in nephrology $[3,4]$. Furthermore, the heterogeneous phenotypic manifestations of these diseases suggest an influence of several genetic and environmental determinants [5]. In fact, unlike monogenic diseases, complex diseases do not show a classic Mendelian inheritance pattern. Generally, each gene involved in a complex disease is responsible only in part for its phenotype and defines simply a "susceptibility" to develop the disorder. The use of high-throughput DNA sequencing technologies appears to be a promising strategy since it permits to obtain a rapid and synchronized analysis of thousands of genes, thus increasing the chance to discover precise disease markers [6]. Furthermore, this quick and efficient diagnostic tool applied to different renal genetic diseases has recently provided a more accurate characterization of specific genetic and molecular patterns that appear also to be involved in the study of nongenetic and very common renal disorders.

This review aims at providing an updated description of the pathogenesis, diagnosis, and available therapeutic options for some rare glomerular and tubular kidney diseases, whose molecular basis might be useful in revealing unrecognized and/or unclear causes of steroid-resistant nephrotic syndrome and primary hypertension.

\section{Steroid-Resistant Nephrotic Syndrome: Has It a Genetic Basis?}

Proteinuria is recognized as a major and independent risk factor for the progression of renal damage [7, 8]. Consequently, the achievement of proteinuria reduction represents one of the most important challenges in nephrology $[7,8]$. Urinary protein excretion exceeding the nephrotic range is associated with a high rate of progres- sion to end-stage renal disease, quality of life worsening, hospitalization, and mortality $[9,10]$. A genetic cause of nephrotic syndrome is always considered in children, whereas in adults, this hypothesis is explored mainly when conventional therapies are ineffective. In recent years, podocyte biology study has been one of the most exciting fields of investigation for an understanding of the physiopathology of nephrotic syndrome (Fig. 1).

Both genetic and molecular alterations associated with the development of massive proteinuria have been identified in experiments conducted in nephrotic syndrome animal models. Pathogenic mutations of genes encoding for filtration barrier proteins, such as podocin, nephrin, and collagen, have been discovered to be associated with nephrotic syndrome in focal and segmental glomerulosclerosis [11].

In 2014, Giglio et al. [12], in a retrospective study conducted by next-generation sequencing technology in 31 children with steroid-resistant nephrotic syndrome and 38 children with steroid-sensitive nephrotic syndrome, explored the possible genetic causes of steroid resistance. Genetic analysis was positive in $32.3 \%$ of children with the steroid-resistant variant of nephrotic syndrome, while no genetic alteration was reported in any of the children with steroid-sensitive disease. Compound heterozygosity or homozygosity of pathogenetic podocyte genes (NPHS2 and PLCE1) has been evidenced. Furthermore, a low podocin expression has been found in the biopsy specimens [12]. In the same year, Bullich et al. [13] reported a similar study conducted in adult patients with steroidresistant nephrotic syndrome due to focal segmental glomerulosclerosis. The results confirmed the presence of 42 pathogenic mutations across NPHS1, NPHS2, WT1, TRPC6, and INF2 genes, all encoding for filtration barrier structural proteins. These findings have proven that steroid resistance has genetic causes with the main phenotypic response being located in the podocyte [13]. These results indicate that patients with steroid-resistant nephrotic proteinuria deserve a genetic counseling and possibly a genetic screening.

\section{Studies on Tubulopathies Provide the Key to Understanding the Mechanisms of Renal Blood Pressure Control}

Essential hypertension is a complex disorder associated with a high mortality risk for cardiovascular comorbidities and CKD development [14]. The pathogenetic basis of hypertension is only partially understood so far,
44

Kidney Dis 2017;3:43-49

DOI: $10.1159 / 000475841$
Simeoni/Damiano/Capolongo/

Trepiccione/Zacchia/Fuiano/Capasso 


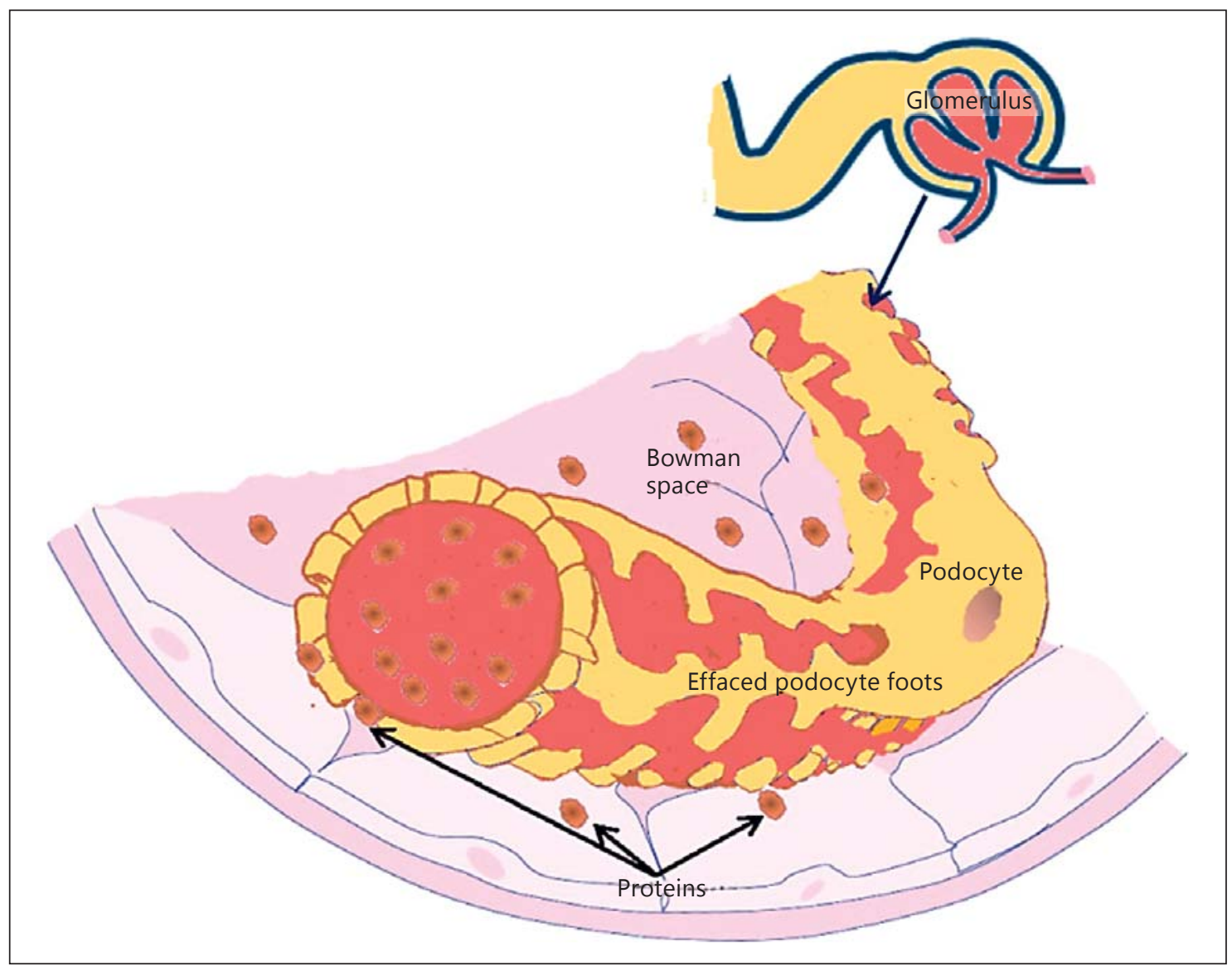

Fig. 1. Impairment of the glomerular filtration apparatus with effacement of podocyte foot and protein passage in the Bowman capsule.

and an association of environmental and genetic factors has been supposed $[15,16]$. Indeed, a close relationship between salt dietary intake and blood pressure levels has been described in several studies. Weinberger et al. [17] were the first to define salt sensitivity based on the results of a study conducted on 378 healthy volunteers and 192 patients with essential hypertension. Blood pressure was measured after $0.9 \% \mathrm{NaCl}$ infusion and after hydrosaline depletion induced by a low-sodium diet and furosemide administration. Compared to normal subjects, patients with hypertension showed higher blood pressure variations after $\mathrm{NaCl}$ administration and only a slight blood pressure reduction after hydrosaline depletion.

Salt sensitivity is, therefore, an individual response to an increased salt intake, and it is possible to divide patients into salt-sensitive and salt-resistant groups. Possible genetic causes of salt sensitivity, probably involving $\mathrm{NaCl}$ renal transporters, have been assumed [18]. In support, the central role exerted by the kidney in the develop- ment of salt intake-related hypertension has been confirmed in cross-kidney transplantation experiments [19].

Renal $\mathrm{Na}^{+}$and $\mathrm{Cl}^{-}$tubular transport is the major mechanism of salt homeostasis maintenance [20]. Several gene mutations encoding different transporters involved in $\mathrm{NaCl}$ tubular handling have been identified and associated with monogenic or syndromic electrolytes and acid-base disorders with an impact on salt-water balance and blood pressure regulation $[21,22]$. The proximal tubule is committed to recover most of the salt freely filtered by the glomerulus, whereas downstream tubular segments are the fine tuning of definitive urinary $\mathrm{NaCl}$ excretion. As a consequence, the regulation of body water content and blood pressure is mainly operated by the distal part of the nephron.

In normal conditions, in the thick ascending limb (TAL) of the loop of Henle, luminal $\mathrm{NaCl}$ enters the cell through the $\mathrm{Na}^{+}-2 \mathrm{Cl}^{-}-\mathrm{K}^{+}$cotransporter (NKCC2) [23], while potassium $\left(\mathrm{K}^{+}\right)$recycles into the lumen via an 
adenosine triphosphate (ATP)-sensitive $\mathrm{K}^{+}$channel (ROMK), assuring the maintenance of NKCC2 activity [24]. $\mathrm{Na}^{+}$ions gain the bloodstream pumped through the basolateral membrane by the $\mathrm{Na}^{+} / \mathrm{K}^{+}$-ATPase system . $\mathrm{Cl}^{-}$, instead, leaves the cell through a basolateral $\mathrm{Cl}^{-}$channel and/or is cotransported with $\mathrm{K}^{+}$. The paracellular reabsorption of $\mathrm{Na}^{+}, \mathrm{K}^{+}, \mathrm{Ca}^{2+}$, and $\mathrm{Mg}^{2+}$ is driven by a lumen-positive transepithelial voltage gradient generated by both the $\mathrm{K}^{+}$recirculation to the lumen and the $\mathrm{Cl}^{-}$basolateral reabsorption [25]. In the distal convoluted tubule, $\mathrm{NaCl}$ cotransporter (NCC) mediates $\mathrm{NaCl}$ reabsorption [26]. Even in this portion of the tubule, $\mathrm{Cl}^{-}$leaves the cell through a specific channel, whereas $\mathrm{Na}^{+}$is pumped in the blood by the $\mathrm{Na}^{+} / \mathrm{K}^{+}$-ATPase system. A specific luminal channel provides the internalization of $\mathrm{Ca}^{2+}$ into epithelial distal tubular cells. Subsequently, $\mathrm{Ca}^{2+}$ is shuttled by Calbindin $28 \mathrm{k}$ to the basolateral membrane and pumped [27] into the blood by a $\mathrm{Na}^{+} / \mathrm{Ca}^{2+}$ exchange and $\mathrm{a} \mathrm{Ca}^{2+}$ ATPase [28].

In the collecting duct, $\mathrm{Na}^{+}$ions are reabsorbed by the principal cell via the luminal $\mathrm{Na}^{+}$channel $(\mathrm{ENaC})$ and exit the basolateral membrane by the $\mathrm{Na}^{+} / \mathrm{K}^{+}$-ATPase system [28]. $\mathrm{Na}^{+}$reabsorption is accomplished with $\mathrm{K}^{+}$ extrusion by ROMK and large $\mathrm{K}^{+}$channels. Through stimulation of its receptor, aldosterone enhances $\mathrm{Na}^{+}$ transport in the collecting duct and, consequently, induces $\mathrm{K}^{+}$loss in the urine [29].

The renin-angiotensin-aldosterone system (RAAS) is the major hormonal regulator of $\mathrm{NaCl}$ tubular transport and provides blood pressure modulation in response to extracellular volume variations [30, 31]. Furthermore, RAAS is described as a pleiotropic system able to exert numerous adjunctive renal and cardiac profibrotic effects, and its upregulation, in hypertensive and proteinuric patients, is associated with the progression of renal and cardiovascular damage $[30,31]$. Several RAAS genetic polymorphisms have also been demonstrated in hypertensive patients with congenital kidney anomalies and progressive CKD [32].

The key role of the RAAS system in blood pressure regulation is prominent in some inherited tubular disorders characterized by reduced or enhanced $\mathrm{Na}^{+}$reabsorption, leading to volume depletion or expansion and consequent activation or suppression of the RAAS system, respectively. On this basis, the study of inherited tubulopathies characterized by an altered tubular salt handling appears useful to extend the knowledge on mechanisms of body volume regulation and to identify possible genetic factors involved in the development of hypertension and salt sensitivity [33].

\section{Hypotensive Syndromes: Bartter and Gitelman Syndromes Mimic Diuretic Activity}

Diuretics are first-choice drugs in the treatment of naivve hypertensive patients in which $\mathrm{NaCl}$ retention and extracellular expansion represent the key mechanisms for high blood pressure onset [34]. The study of altered $\mathrm{NaCl}$ mechanisms underlying hypotensive genetic tubulopathy development aids in understanding the mechanisms of diuretic-related blood pressure reduction, abnormal responses to diuretics, and the development of side effects [35]. Furthermore, the knowledge of genetically impaired $\mathrm{NaCl}$ transport mechanisms might contribute to the identification of possible inherited pathways associated with so-called "essential hypertension."

In 1962, Bartter et al. [36] first reported a genetic syndrome characterized by altered $\mathrm{NaCl}$ handling in the TAL in 2 homozygous twin sisters. Bartter syndrome is characterized by a normotensive/hypotensive phenotype associated with hypokalemia, hypochloremic alkalosis, hypocalcemia, and hyperplasia of the juxtaglomerular apparatus. So far, 5 genetic Bartter syndrome variants have been found to be associated with different loss-of-function mutations of genes encoding electrolyte transporters in the TAL (Fig. 2a). In particular, Bartter syndrome is characterized by $\mathrm{NaCl}$ urinary waste, extracellular fluid volume reduction, and hypotension, despite the coexistence of hyperaldosteronism. Type 1 Bartter syndrome is induced by loss-of function mutations of the SLC12A1 gene inhibiting NKCC2 activity and mimicking furosemide pharmacodynamics [37]. Instead, type 2 Bartter syndrome is associated with mutations in the KCNJ1 gene encoding the apical ROMK in the TAL. The decrease in ROMK activity induces a reduction of $\mathrm{K}^{+}$back-filtration in the lumen and, again, inhibits NKCC2 activity. CLCNKB gene mutations are responsible for chloride voltage-gated channel $\mathrm{Kb}$ (CLCNKB) blockage and are associated with type 3 Bartter syndrome. Mutations of the CLCNKB and CLCNKA genes encoding for basolateral $\mathrm{Cl}^{-}$channel or mutations of the BSND gene encoding the Barttin subunit of the channel induce type 4 Bartter syndrome, which is characterized by deafness associated with Bartter syndrome. The impairment of $\mathrm{Cl}^{-}$channels, in fact, leads to reduced renal salt reabsorption and potassium recycling in the inner ear [38].

Type 5 Bartter syndrome has recently been discovered and described to be associated with a gain-of-function mutation of the K29E gene encoding the extracellular $\mathrm{Ca}^{2+}$-sensing receptor (CaSR) [39]. This Bartter-like syn-
Kidney Dis 2017;3:43-49

DOI: $10.1159 / 000475841$
46
Simeoni/Damiano/Capolongo/

Trepiccione/Zacchia/Fuiano/Capasso 


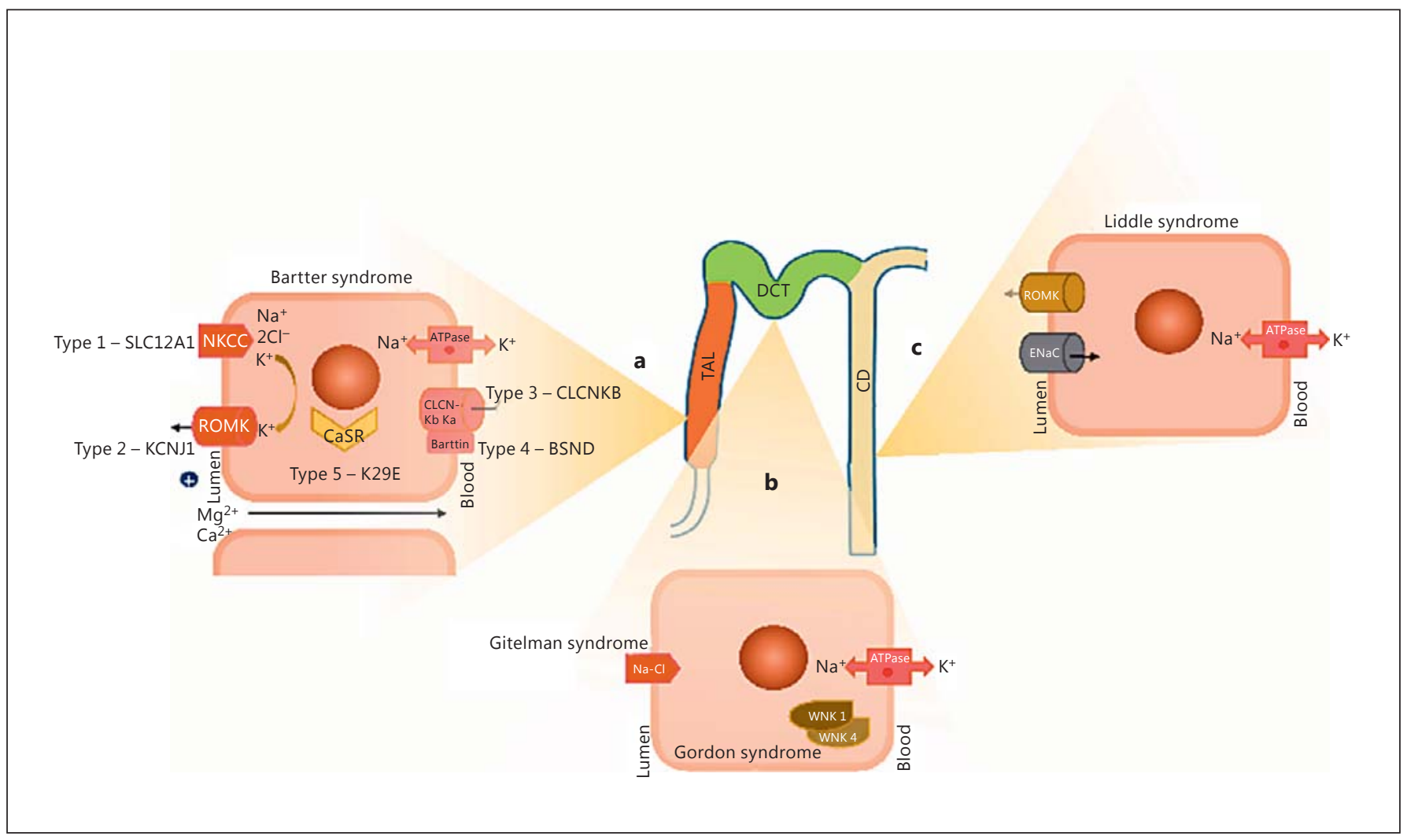

Fig. 2. Along the tubular portion of the nephron, the mutated malfunctioning cell sites in Bartter syndrome (a), in Gitelman and Gordon syndrome (b), and in Liddle syndrome (c) are depicted.

drome is characterized by a mild phenotype due to the enhanced inhibition exerted by CaSR activity on sodium transport in the TAL [40].

Another hypotensive tubulopathy is Gitelman syndrome, whose pathogenetic basis is due to altered salt handling in the distal convoluted tubule, which mimics thiazide diuretics pharmacodynamics (Fig. 2b). In fact, linkage studies have demonstrated that Gitelman syndrome is induced by loss-of-function mutations of the locus encoding the apical NCC. In Gitelman syndrome, in fact, conversely to Bartter syndrome, hypotension, hypokalemia, and hypochloremic alkalosis are associated with hypomagnesemia and hypocalciuria [41].

Genetic mutations mirroring those identified in the hypotensive tubulopathies could explain cases of hypertension with variable response to conventional diuretic therapy [42]. Thus, a careful electrolytes and acid-base study and, eventually, a genetic counseling might be indicated in naïve patients with "essential" hypertension showing an abnormal response to salt dietary restriction and to diuretic stimulation.

Rare Kidney Diseases

\section{Mendelian Hypertensive Tubulopathies: Mechanisms of Blood Pressure Increase}

Advanced genomic techniques have permitted the identification of rare monogenic forms of hypertension characterized by either disorders of distal $\mathrm{NaCl}$ transport or dysregulation of mineralocorticoid hormone secretion/activity. Liddle syndrome is an autosomal dominant form of hypertension in which gain-of-function mutations of a single gene encoding $\beta$ or $\gamma$ subunits of the amiloride-sensitive epithelial $\mathrm{ENaC}$ of the principal cells in the collecting duct are associated with early onset of severe hypertension, hypokalemia, metabolic alkalosis, and hypoaldosteronism (Fig. 2c). Hypokalemia and metabolic alkalosis depend on the absence of a lumen-positive gradient in the collecting duct. This luminal electronegativity is due to the excessive $\mathrm{Na}^{+}$reabsorption by $\mathrm{ENaC}$ that inhibits both $\mathrm{K}^{+}$and $\mathrm{H}^{+}$transepithelial transport and increases the urinary loss of the 2 cations. Treatment of Liddle syndrome with amiloride or triamterene is effective in blocking $\mathrm{ENaC}$ hyperactivity in the collect-

Kidney Dis 2017;3:43-49 47 
ing tubule. Instead, spironolactone does not correct electrolyte and acid-base disorders in Liddle syndrome because the increased activity of the $\mathrm{ENaC}$ is aldosterone independent [43]. Thus, in patients with essential hypertension, a diversified response to different $\mathrm{K}^{+}$-sparing diuretics might deserve a careful diagnostic study, possibly including genetic insights.

Gordon syndrome or pseudohypoaldosteronism type II is a rare familial autosomal dominant disease caused by mutations of WNK1 and WNK4, 2 proteins of a serinethreonine kinases family that have recently been identified [44] (Fig. 2b). In the distal tubule, wild-type WNK1 and WNK4 inhibit NCC, whereas gain-of-function mutations stimulate NCC activity, inducing excessive $\mathrm{NaCl}$ reabsorption and volume expansion. Consequently, the Gordon syndrome phenotype is characterized by tardive onset of severe hypertension, low fractional $\mathrm{Na}^{+}$excretion, and hyperchloremic metabolic acidosis in patients showing short height, muscle weakness, dental abnormalities, and cognitive defects [45]. The therapeutic approach aims at decreasing NCC activity also by limiting the substrate for $\mathrm{NaCl}$ transport. As a consequence, thiazide diuretics and a low-salt diet are mandatory in the treatment of Gordon syndrome. Different mutations or milder phenotypes may also be supposed in hypertensive patients that show a reduced response to nonthiazide diuretics.

\section{Conclusions}

Rare kidney diseases are an interesting field of investigation, especially because different pathogenic molecular pathways are only partially characterized. However, causes of several genetic kidney diseases have recently been evidenced by the use of advanced technologies for gene sequencing. Undoubtedly, many similarities with the pathogenesis of the most common kidney disorders are evident. Apparently, the complex pathogenesis of common kidney diseases associated with the onset and progression of CKD may have a genetic background that could be investigated starting from the study of rare kidney diseases. A genetic background for steroid resistance in nephrotic syndrome could be supposed, and several pathogenetic mutations impairing the glomerular filtration barrier integrity have been found only in nephrotic patients not responding to corticosteroids. Similarly, the response to antihypertensive drugs and to salt intake modifications is individual in hypertensive patients, and genetic mutations interfering with $\mathrm{NaCl}$ tubular handling might be a valid explanation. The characterization of hypotensive and hypertensive tubulopathies might indicate new investigation areas for a better understanding of the mechanisms of hypertension development and maintenance, thus providing precision therapeutic approaches.

\section{Conflict of Interest Statement}

The authors declare no conflicts of interest.

\section{References}

1 Shayman JA: Thinking about rare kidney diseases. J Am Soc Nephrol 2006;17:15-16.

2 Renkema KY, Stokman MF, Giles RH, Knoers $\mathrm{NV}$ : Next-generation sequencing for research and diagnostics in kidney disease. Nat Rev Nephrol 2014; 10:433-444.

3 Levey AS, Atkins R, Coresh J, Cohen EP, Collins AJ, Eckardt KU, Nahas ME, Jaber BL, Jadoul M, Llevin A, Powe NR, Rossert J, Wheeler DC, Lameire R, Eknoyan G: Chronic kidney disease as a global public health problem: approaches and initiatives - a position statement from Kidney Disease Improving Global Outcomes. Kidney Int 2007;72:247-259.

4 Levey AS, Andreoli SP, DuBose T, Provenzano R, Collins AJ: Chronic kidney disease: common, harmful and treatable - World Kidney Day 2007. Am J Kidney Dis 2007;49:175179.

5 Coppolino G, Simeoni M, Summaria C, Postorino MC, Rivoli L, Strazzulla A, Torti C, Fui- ano GJ: The case of chronic hepatitis B treatment with tenofovir: an update for nephrologists. Nephrol 2015;28:393-402.

6 Drmanac R: The advent of personal genome sequencing. Genet Med 2011;13:188-190.

7 Simeoni M, Cianfrone P, Comi N, Gentile I, Fabiano FF, Piraina V, Talarico R, Lucisano G, Rivoli L, Andreucci M, Fuiano L, Foti D, Gulletta E, Fuiano G: Is it feasible to improve the duration and the efficiency of Ramipril anti-proteinuric response? (in Italian). G Ital Nefrol 2015;32.

8 Cianfrone P, Simeoni M, Comi N, Piraina V, Talarico R, Cerantonio A, Gentile I, Fabiano FF, Lucisano G, Foti D, Gulletta E, Fuiano G: How to improve duration and efficiency of the antiproteinuric response to Ramipril: RamiPROT - a prospective cohort study. J Nephrol 2015;30:95-102.

9 Ruggenenti P, Perna A, Mosconi L, Pisoni R, Remuzzi G: Urinary protein excretion rate is the best independent predictor of ESRF in non-diabetic proteinuric chronic nephropathies. Kidney Int 1998;53:1209-1216.

10 D’Onofrio G, Simeoni M, Rizza P, Caroleo M, Capria M, Mazzitello G, Sacco T, Mazzuca E, Panzino MT, Cerantonio A, Segura-Garcia C, Andreucci M, De Fazio P, Fuiano G: Quality of life, clinical outcome, personality and coping in chronic hemodialysis patients. Ren Fail 2017;39:1:45-53.

11 Simic I, Tabatabaeifar M, Schaefer F: Animal models of nephrotic syndrome. Pediatr Nephrol 2013;28:2079-2088.

12 Giglio S, Provenzano A, Mazzinghi B, Becherucci F, Giunti L, Sansavini G, Ravaglia F, Roperto LM, Farsetti F, Benetti E, Rotondi M, Murer L, Lazzeri E, Lasagni L, Materassi M, Romagnani P: Heterogeneous genetic alterations in sporadic nephrotic syndrome associate with resistance to immunosuppression. J Am Soc Nephrol 2015;26:230-236.
48

Kidney Dis 2017;3:43-49 DOI: $10.1159 / 000475841$
Simeoni/Damiano/Capolongo/

Trepiccione/Zacchia/Fuiano/Capasso 
13 Bullich G, Trujillano D, Santìn S, Ossowski S, Medizàbal S, Fraga G, Madrid A, Ariceta G, Balarìn J, Torra R, Estivill X, Ars E: Targeted next-generation sequencing in steroid-resistant nephrotic syndrome: mutations in multiple glomerular genes may influence disease severity. Eur J Hum Genet 2015;23:11921199.

14 Carretero O, Oparil S: Essential hypertension. Circulation 2000;101:329-335.

15 Bullet MG: Genetics of hypertension. Current status. J Med Liban 2010;58:175-178.

16 Lang F, Capasso G, Schwab M, Waldegger S: Renal tubular transport and the genetic basis of hypertensive disease. Clin Exp Nephrol 2005;9:91-99.

17 Weinberger MH, Miller JZ, Luft FC, Grim CE, Fineberg LS: Definitions and characteristics of sodium sensitivity and blood pressure resistance. Hypertension 1986;8:II127-II134.

18 Capasso G, Cantone A, Evangelista C, Zacchia M, Acone D, Trepiccione F, Rizzo M: Channels, carriers, and pumps in the pathogenesis of sodium-sensitive hypertension. Semin Nephrol 2005;25:419-424.

19 Sanada H, Jones JE, Jose PA: Genetics of saltsensitive hypertension. Curr Hypertens Rep 2011;13:55-66.

20 Berry CA, Rector FC Jr: Mechanism of proximal $\mathrm{NaCl}$ reabsorption in the proximal tubule of the mammalian kidney. Semin Nephrol 1991;11:86-97.

21 Lang F, Capasso G, Schwab M: Renal tubular transport and the genetic basis of hypertensive disease. Clin Exp Nephrol 2005;9:91-99.

22 Capasso G, Rizzo M, Evangelista C, Ferrari P, Geelen G, Lang F, Bianchi G: Altered expression of renal apical membrane $\mathrm{Na}^{+}$transporters in the early phase of genetic hypertension. Am J Physiol Renal Physiol 2005;288:F1173F1182.

23 Gamba G, Friedman PA: Thick ascending limb: the $\mathrm{Na}^{+}: \mathrm{K}^{+}: 2 \mathrm{Cl}^{-}$co-transporter, NKCC2, and the calcium-sensing receptor, CaSR. Pflugers Arch 2009;458:61-76.

24 Sun A, Grossman EB, Lombardi M, Hebert SC: Vasopressin alters the mechanism of apical $\mathrm{Cl}^{-}$entry from $\mathrm{Na}^{+}: \mathrm{Cl}^{-}$to $\mathrm{Na}^{+}: \mathrm{K}^{+}: 2 \mathrm{Cl}^{-}$cO- transport in mouse medullary thick ascending limb. J Membr Biol 1991;120:83-94.

25 Subramanya AR, Hellison DH: Distal convoluted tube. Curr Hypertens Rep 2011;13:5566.

26 Palmer LG, Schnermann J: Integrated control of Na transport along the nephron. Clin J Am Soc Nephrol 2015;10:676-687.

27 Rizzo M, Capasso G, Bleich M, Pica A, Grimaldi D, Bindels R, Greger R: The effect of chronic metabolic acidosis on calbindin expression along the rat distal tubule. J Am Soc Nephrol 2000;11:203-210.

28 Blaine J, Chonchol M, Levi M: Renal control of calcium, phosphate, and magnesium homeostasis. Clin J Am Soc Nephrol 2015;10: 1257-1272.

29 Suhail $\mathrm{M}: \mathrm{Na}^{+}, \mathrm{K}^{+}$-ATPase: ubiquitous multifunctional transmembrane protein and its relevance to various pathophysiological conditions. J Clin Med Res 2010;2:1-17.

30 Simeoni M, Cerantonio A, Pastore I, Liguori R, Greco M, Foti D, Gulletta E, Brunetti A, Fuiano G: The correct renal function evaluation in patients with thyroid dysfunction. J Endocrinol Invest 2016;39:495-507.

31 Simeoni M, Nicotera R, Colao M, Citraro ML, Pelagi E, Cerantonio A, Comi N, Coppolino G, Fuiano G: Direct inhibition of plasmatic renin activity with Aliskiren: a promising but under-investigated therapeutic option for non-diabetic glomerulonephritis. Int Urol Nephrol 2016;48:229-237.

32 Wong C, Kanetsky P, Raj D: Genetic polymorphisms of the RAS-cytokine pathway and chronic kidney disease. Pediatr Nephrol 2008; 23:1037-1051.

33 Zelikovic I: Hypokalaemic salt-losing tubulopathies: an evolving story. Nephrol Dial Transplant 2003;18:1696-1700.

34 Psaty BM, Lumley T, Furberg CD, Schellenbaum G, Pahor M, Alderman NH, Weiss NS: Health outcomes associated with various antihypertensive therapies used as first-line agents: a network meta-analysis. JAMA 2003; 289:2534.

35 Unwin RJ, Capasso G: Bartter's and Gitelman's syndromes: their relationship to the ac- tions of loop and thiazide diuretics. Curr Opin Pharmacol 2006;6:208-213.

36 Bartter FC, Pronove P, Gill JR: Hyperplasia of the juxtaglomerular complex with hyperaldosteronism and hypokalemic alkalosis. A new syndrome. Am J Med 1962;33:811-828.

37 Shibli AA, Narchi H: Bartter and Gitelman syndromes: spectrum of clinical manifestations caused by different mutations. World J Methodol 2015;5:55-61.

38 Amirlak I, Dawson KP: Bartter syndrome: an overview. QJM 2000;93:207-215.

39 Capasso G, Geibel PJ, Damiano S, Jaeger P, Richards WG, Geibel JP: The calcium sensing receptor modulates fluid reabsorption and acid secretion in the proximal tubule. Kidney Int 2013;84:277-284.

40 Vezzoli G, Arcidiacono T, Paloschi V, Terranegra A, Biasion R, Weber G, Mora S, Syren ML, Coviello D, Cusi D, Bianchi G, Soldati L: Autosomal dominant hypocalcemia with mild type 5 Bartter syndrome. J Nephrol 2006; 19:525-528.

41 Cotovio P, Silva C, Oliveira N, Costa F: Gitelman syndrome. BMJ Case Rep 2013, DOI: 10.1136/bcr-2013-009095.

42 Capasso G, Rizzo M, Garavaglia ML, Trepiccione F, Zacchia M, Magione A, Ferrari P, Paulmichl M, Lang F, Loffing J, Carrel M, Damiano S, Wagner CA, Bianchi G, Meyer G: Up-regulation of apical sodium chloride cotransporter and basolateral chloride channels are responsible for the maintenance of salt sensitive hypertension. Am J Physiol Renal Physiol 2008;295:F556-F567.

43 Cui Y, Tong A, Jiang J, Wang F, Li C: Liddle syndrome: clinical and genetic profiles. J Clin Hypertens (Greenwich) 2016, DOI: 10.1111/ jch.12949.

44 Bruel A, Vargas-Poussou R, Jeunemaitre X, Labbe A, Merlin E, Bessenay L: Gordon syndrome: the importance of measuring blood pressure in children. Arch Pediatr 2016;23: 827-831.

45 Cantone A, Wang T, Pica A, Simeoni M, Capasso G: Use of transgenic mice in acid-base balance studies. J Nephrol 2006;(suppl 9):S121-S127. 